\title{
HR Metrics and Talent Analytics
}

\author{
Alexis A. Fink and Michael C. Sturman \\ [Chapter prepared for Oxford Handbook of Talent Management, \\ Editors: David G Collings, Kamel Mellahi, and Wayne F. Cascio]
}

\section{Introduction}

Once again, there is buzz about organizations working to apply numbers to managing their talent. The opportunities created by "big data' in human resources (HR), along with the continuous pressure for greater effectiveness and productivity, have renewed calls for more analytical HR management as the way of the future. But we have heard this call in HR many times. We heard it associated with HR accounting in the 1970s (e.g., Flamholtz, 1999), utility analysis in the 1980s (e.g., Boudreau, 1991; Cascio, 1981), HR scorecards in the 1990s (e.g., Becker, Huselid, and Ulrich, 2001), and HR metrics in the 2000s (e.g., Boudreau and Ramstad, 2007). Is there really anything new today or is this just the same old analytical angst wrapped up in fresh and different colorful wrappings? A cynical view of HR's analytical history may suggest recurring rounds of clarion calls for quantifiable approaches to HR, each one leading to a new dead end where the promises of greater sophistication are not fulfilled because of the limitations in the data and decision makers at whom the advances are targeted. In this chapter, however, we argue that this history is indicative of an evolving decision science (Boudreau and Ramstad, 
2007). We see the combination of current technologies, past experiences, and varied analytical approaches to HR leading to a new set of emerging methods and tactics. This chapter shows that, while the field of HR is still far from a definitive resolution to its analytical challenges, we can learn from the various efforts to quantify HR, combining and coordinating these efforts to yield a better understanding of the various ways analytical HR processes build upon each other. We argue that the union of past analytical approaches to HR with a recognition of the opportunities presented today, owing to technology and data availability, culminates in what is now known as talent analytics.

Many may be challenged to define talent analytics, let alone differentiate it from HR metrics and other jargon of the near and far past. For the purposes of this chapter, we are treating HR metrics as an operational measurement. HR metrics addresses how efficient, effective, and impactful an organization's HR practices are. That is, HR metrics quantify waste in programs and investments (efficiency), whether programs deliver the outcomes planned (effectiveness), and whether those outcomes have a material effect on the firm (impact) (Boudreau and Ramstad, 2007; Dulebohn and Johnson, 2013). In contrast, talent analytics focus on decision points, guiding investment decisions (Boudreau and Ramstad, 2007; Fitz-Enz, 2010). Whereas HR metrics tell you about "what" is going on, talent analytics gets at the decision-making about HR, driven by both good data and good science (Boudreau and Ramstad, 2007). Thus, metrics are about getting the numbers right, and analytics are about finding answers in the data (Cascio and Boudreau, 2011; Levenson, 2015).

Unfortunately, practitioners wishing to deliver excellent HR metrics, let alone a talent analytics system, don't have much to go on in the way of guidance. Despite repeated calls for HR research to help drive evidence-based management (Briner and Rousseau, 2011; Rousseau, 
2006), the gap between research and practice with regard to talent analytics remains quite extensive (Dulebohn and Johnson, 2013). Quite arguably, even state-of-the-art research often lacks clear practical applicability. For example, issues of scale create an additional layer of complexity between primary research, often done with controlled samples of modest size, and complex organizations that may vary in size from hundreds of thousands to fewer than twenty (Cascio and Boudreau, 2014). Conversely, practices developed at leading organizations and covered in the business press may be difficult to translate into different organizational contexts. Thus, while there may be clear consensus for the need for talent analytics, implementation remains a major problem.

The purpose of this chapter is to provide an overview of the historic roots and current practices around HR metrics and talent analytics in organizations. Over the course of this discussion, we will review the distinctions between HR metrics and talent analytics, as well as the distinctions among different types of HR metrics, such as efficiency, effectiveness, and impact. We'll also explore the role, benefits, and risks of benchmarking and utility analyses as two common approaches to setting HR metrics in organizations. We will close with a discussion on fostering talent analytics within organizations, as a natural outgrowth and companion to a robust HR metrics portfolio.

\section{Current Practical and Theoretical Approaches}

Basic HR data points, such as overall headcount or payroll expenditures, should not be confused with HR metrics. While these are nearly ubiquitous, and clearly are reporting HRrelated information, these sorts of measures don't capture HR effectiveness. Cascio and 
Boudreau (2011) refer to this most fundamental level of sophistication as "counting:' Reports that simply reflect numbers like these quantify the workforce, but don't add much value in terms of informing judgments about how well HR is doing as a function. Thus, we make a distinction between basic HR reporting, which captures basic facts about an organization or team and has value in helping managers and leaders track and manage their own teams and workforces, and HR metrics, which help HR and the organization evaluate the efficiency, effectiveness, and impact of their HR systems, programs, and processes. Cascio and Boudreau (2011) refer to this greater level of HR sophistication as both "clever counting" (which extrapolates from descriptive data to yield new insights) and "insight" (which helps reveal the drivers of trends discovered through "clever counting"). HR reporting quantifies the current state, and HR metrics add an evaluative component that tells us how well HR is performing for a particular function.

\subsection{Benchmarking}

In seeking to build measurement systems for HR and to improve HR functioning through measurement, practitioners often turn first to benchmarking. Benchmark information is readily available through consultants, nonprofit organizations, and specialized reporting groups, and benchmarks are available for a vast array of HR items (Becker, Huselid, and Ulrich, 2001; Dulebohn and Johnson, 2013). Benchmarks provide a ready-made bundle of evaluation methods and target values that can be appealing. For example, the Society for Human Resources Management offers a library of benchmarking reports, toolkits, and calculators as one of its services (e.g., Dooney, 2013). The Saratoga Institute, an innovator in HR benchmarking nearly a half-century ago and now a part of PWC, offers a dizzying array of metrics and custom benchmarking solutions (cf. PWC, 2015). Social comparison is a strong human urge and, at least intuitively, comparing one's processes or own performance to those of peers seems like a useful 
first step. Benchmarking studies can help organizations identify areas in their HR systems that are atypical, although benchmarking alone may not be able to help organizations determine whether that is an atypical result of failure that should be mitigated or a strategic investment that should be preserved (Levenson, 2015). Additionally, benchmarking studies, whether from consulting firms or organizations like the Conference Board, are often accompanied by bestpractice sharing. These are often presented as small case studies. Many benchmarking studies will highlight practices from multiple organizations to highlight different approaches, or different nuances to the same general approach. This can serve as a source of inspiration.

Benchmarking, while dominant, is an imperfect approach to HR metrics. Benchmarking studies often do not include rigorous evaluation of the practices being highlighted. Further, many benchmarking studies are produced by consulting firms with a clear commercial interest in the practices being touted. Benchmarking is further complicated in that organizational context and strategy are typically lost in the process. Benchmarking can run the risk of contributing to a mindless "me too" mentality that wastes resources. By its very nature, benchmarking facilitates the process of one organization copying the processes and results of another organization, which contrasts directly with the concept of developing a sustained competitive advantage (Bromiley and Rau, 2015; Hitt, Carnes, and Xu, 2015). Indeed, the best a firm could ever hope to be, if it relies only on benchmarking, is a composite of elements from other firms; yet, competitive advantage comes from doing something different from everyone else.

While excessive attention to benchmarking can be a net negative for organizations, the specific calculations used in many studies can provide clarity and inspiration for developing HR metrics and ultimately developing a talent analytics system. That is, while the specific benchmark practices or target scores on metrics may not be suited to a particular organization's 
strategy or situation, borrowing or gaining inspiration from benchmarked methods of calculation can speed the process of developing and finalizing the optimal suite of metrics for a given organization. For example, a medium-sized, stable organization with low turnover and limited internal movement, operating in a single line of business, is likely to need different levels of successor bench strength, as measured by ready-now candidates, and likely to need a different efficiency profile in investing in those select few candidates than a fast-growing, global business with 30\% turnover and multiple, diverse business lines. However, the two organizations could learn from one another in the methods they use to evaluate their succession-planning system, such as perhaps judging efficiency of succession-planning investments in terms of dollars spent per successor placed, rather than dollars spent per potential successor. While the target dollars per placement would likely differ for the two organizations, the focus on efficiency of investment per outcome (successors placed) may help both organizations avoid imbalanced investments that leave them with too many potential successors in one part of an organization and too few in another.

\subsection{Balanced Scorecards}

Some organizations have applied Balanced-scorecard (Kaplan and Norton, 1992) thinking to their talent systems. Balanced scorecards have helped the cause of HR metrics in that they pushed organizations to measure and manage non-financial items. Some organizations have even applied balanced scorecards to their talent systems (e.g., Becker, Huselid, and Ulrich, 2001), and many scorecards specifically take into account HR measures (e.g., Denton and White, 2000). Given that HR topics are often included in a balanced scorecard, organizations using them typically have at least perfunctory HR metrics systems. 
Many HR organizations build and publish slates of key metrics, such as cost per hire, span-of-control ratios, success rate of employee referrals versus other hire sources, percentage of high potentials promoted in a given year, employee engagement, training spend per employee, or attrition among top versus low performers. Depending on the priorities of the organization and the maturity of the measurement system, balanced scorecards may include basic reporting, performance against external benchmarks, or performance against internal standards of efficiency, effectiveness, and impact. HR scorecards will be composed, at least in part, by HR metrics, ideally chosen in such a way that helps explain and drive valued organizational outcomes.

A simpler HR scorecard, based on reporting efficiency metrics, might include such things as attendance, cost per hire, number of hires, number of exits, or number of training days (Huselid, Becker, and Beatty, 2005). These reporting approaches often include a backwardlooking component, such as percentage change from a prior period, for example, the prior month, quarter, or year. However, while those backward-looking comparisons are provided, the reporting system itself does not generally add a value judgment to the metrics reported in these schemes, and, under different business conditions, the same number could have a very different meaning. Scorecards that are more sophisticated may include measures of effectiveness or even outcomes. Such scorecards could contain metrics such as percentage turnover by performance level, percent of workforce that is promotable, retention of core competency workforce, proportion of workforce possessing requisite skill levels, increase in sales attributable to a training program, reduction in turnover attributable to a new orientation system, and others (cf., Huselid, Becker, and Beatty, 2005). Regardless of the level of sophistication, the scorecards are most typically divided by HR functional area-staffing, employee relations, and so forth-and 
rarely sum to an overall measure. Indeed, where systems are composed largely of reporting, such a sum would be nonsensical.

Often, HR scorecards include a target value and a scoring schema to indicate trouble areas (Huselid, Becker, and Beatty, 2005). For example, the target number of days to fill an open requisition might be thirty-eight, and that line on a scorecard may be coded as green if it is thirtyeight or fewer, yellow if it is thirty-nine to forty-five days (15\% over target), and red if it is fortyfive days or longer. HR organizations that use this approach will often regularly assess performance against those target values or goals, most often with a simple color-coding scheme as noted in this example. Simple color codes allow quick attention to focus on problematic items. However, even setting those simple color codes can become fraught as practitioners determine, for example, if yellow means "in danger of being worse than target" or "slightly worse than target, but still recoverable;' and as the size of the ranges around a target are set.

Organizations can set their goals based on external comparisons, such as performance against an external benchmark or industry standard, or based on internal strategies. It is unfair to oversimplify and suggest that sophisticated organizations use their own standards and unsophisticated ones "chase the taillights" of the industry leaders. A thoughtful approach to HR metrics will generally incorporate target values or goals from a variety of sources, both internal and external, depending on the strategic importance and uniqueness of the items in question (Huselid, Becker, and Beatty, 2005). Thus, a well-built HR scorecard is likely to include some external benchmark information as well as some internal references, and that same scorecard is likely to reflect a mix of efficiency, effectiveness, and impact measures. The more that an HR scorecard is tailored to the specific characteristics and HR strategy of a given organization, though, the more likely it is that internal comparisons will be needed over external benchmarks. 
It is easier to benchmark "time to fill:' for example, than it is to benchmark the ROI from a sales training program.

\subsection{Research-Based Approaches}

There is actually quite a long history to HR metrics from the academic literature (e.g., Brogden, 1949; Cronbach and Gieser, 1957; Taylor and Russell, 1939). Repeated efforts have been made to create a mechanism that links individual behaviors and organizational value. Perhaps the most historically prominent among these approaches are Kirkpatrick's (1959) framework of learning evaluation-which provides an approach for conceptualizing different ways in which an HR intervention has effects at different levels of impact-and utility analysis, which applies mathematical conventions to assign a monetary value to an intervention's effect on organizational outcomes (Cascio and Boudreau, 2014; Sturman, 2012).

\subsubsection{Kirkpatrick's Model of Learning Evaluation}

Theoretical taxonomies have been put forth for nearly every corner of HR practice. These often reflect the maturity of a particular process, and are very useful in providing a language for debate internally as strategic decisions are made. It is logical to apply the same models that influenced the design of a system or program to measurement of that system or program.

Kirkpatrick (1959) created a now classic model that outlined four levels of learning evaluation (reactions, learning, behaviors, and outcomes or results). Each higher level is purported to be progressively more useful, but also increasingly difficult to implement. Despite long-standing evidence questioning the assumptions behind this model (cf. Alliger and Janak, 1989; Holton, 1996; Snyder, Raben, and Farr, 1980), it continues to be regularly employed in the evaluation of training (e.g., Grohmann and Kauffeld, 2013; Salas, Wildman, and Piccolo, 2009; 
Taras et al., 2013; Yorks, Beechler, and Ciporen, 2007). The first two levels-reactions and learning-account for the vast majority of learning-measurement projects (Grohmann and Kauffeld, 2013; Kirkpatrick and Kirkpatrick, 2005; Noe, 2013; Salas, Wildman, and Piccolo, 2009). This is not because organizations don't believe that changing behavior and ultimately getting results are not important outcomes; rather, such measurement is more challenging logistically and from a design standpoint. Despite Kirkpatrick's more than 10,000 citations for this model (according to Google Scholar), the high-level evaluation of HR training programs remains an elusive goal.

Outcome data are often not easily available, and by definition, they require time to collect and analyze. As is often the case, organizations focus on what is easy to measure, which, at times, can be counterproductive (Kerr, 1975). Managers may also want to include metrics they know they can do well on, or focus their efforts on achieving better scores on the metrics at the expense of other parts of their jobs that are not well measured. Indeed, there is a large body of literature describing how individuals use various impression-management tactics in order to increase performance ratings (cf. Bolino, Kacmar, Turnley, and Gilstrap, 2008). Measuring and rewarding specific metrics will likely encourage managers to behave in ways that increase scores on those metrics. A well-designed system can be quite productive. But if the set of metrics is not complete, or if the incentives are such that they encourage unethical behaviors in order to manipulate the metrics, then such measurement systems may actually cause more harm than good in the long run.

Continuing the Kirkpatrick example, some organizations surely focus on reactions (did participants like the training?) and learning (did participants gain knowledge from the training?) because they do well on those measures, and can more directly influence them. Changes in 
behavior and the resulting ultimate change in performance are influenced by many factors, and they are much less certain as results of learning interventions. Thus, organizations may intend to invest in the higher-level outcomes, but as long as measurement systems focus on the lower-level outcomes, they are less likely to achieve their stated objectives. Ironically, there may even be an inverse relationship between achieving the stated objectives and driving measurement, so long as that measurement is focused on a different part of the system. For example, imagine a company is sending high-level managers to an off-site location for a training program designed to enhance their financial analytical skills. For this, the company would likely want an intensive program that effectively teaches high-level financial concepts and gives the trainees practice with difficult problems so they can apply the skills when they return to their positions. But if the training program is evaluated purely based on reactions (as opposed to learning, behaviors, or outcomes), it is highly plausible that an entertaining course with a light workload (and plenty of time for the trainees to enjoy the site's amenities) would be rated more positively than would an intensive and challenging course that makes the trainees work long hours, devote considerable mental energy to the course, and miss out on all those nice amenities at the training location.

The opportunity to finally, truly capture the full robustness of data required to deliver compelling HR metrics may be found in the emergence of new data sources and analytic methods brought about by increases in computing power and innovations in data capture. With so much of modern work being digital, data-mining technologies can be used to evaluate data on engagement, sales activities, personality variables, and other work efforts to create metrics of individual performance (Chamorro-Premuzic, Winsborough, Sherman, and Hogan, 2016). At the same time, we are seeing technology advances that allow personality to be predicted from mobile phone records (de Montjoye, Quoidbach, Robie, and Pentland, 2013) or with social media 
information (Lambiotte and Kosinski, 2014). Phone records can also be used to predict employees' stress (Bogomolov et al., 2014). Increasingly, HR information systems are integrating with other workplace computer systems and building not only HR reporting but also HR metrics into their out-of-the-box offerings. All of this suggests that automated methods for assessing individuals can be used to evaluate the behavioral changes and results attributable to training (or other HR) interventions.

\subsubsection{Human Resource Accounting}

According to the American Accounting Associations Committee on Human Resource Accounting (1973), HR accounting is "the process of identifying and measuring data related to HR and communicating this information to interested parties:' Given the importance of an organizations employees for its own success, it would be valuable to have the means to understand the cost of developing human capital and the return on investment from training and development (Cherian and Farouq, 2013). Over the years, a body of research, techniques, and tools has emerged to help make the ideas of HR accounting feasible to implement (Flamholtz, 1999).

Research on HR accounting has sought to create a means to measure the value of employee talent, ultimately with the intent of helping drive better investment decisions in human capital and deepening our understanding of the implications of HR decisions (Flamholtz, 1999). Unfortunately, despite research on the topic and many advances over the years, companies (and HR professionals) are not willing to engage in HR accounting (Cherian and Farouq, 2013). The fundamental need of HR accounting was an objective measure representing employee value, but it never fully materialized (Cascio and Boudreau, 2011; Mirvis and Lawler, 1983; Roselender and Dyson, 1992; Scarpello and Theeke, 1989). So, as Scarpello and Theeke noted more than 
twenty-five years ago, while "at the theoretical level, HR accounting is an interesting concept" (1989: 275), its use as a decision aid remains negligible. The few studies we occasionally see today continue to indicate a lack of awareness of HR accounting, as well as other major obstacles to its implementation (cf. Paki and Azar, 2015), and others cite many continuing impediments despite the appeal of fulfilling HR accounting's goals (Cherian and Farouq, 2013).

\subsubsection{Utility Analysis}

Another longstanding effort to quantify the impact of HR is utility analysis. With utility analysis, HR works to speak the language of business, calculating the value of specific investments in the HR system. By quantifying the value of employee performance and estimating the effect of HR interventions on the bottom line through their influence on employee performance, utility analysis provides an estimate of the result (e.g., the fourth level of Kirkpatrick's framework) of HR interventions (Sturman, 2012).

One of the great strengths of utility analysis is that it explicitly addresses HR expenditures and resource commitments, not as costs, but as investments in outcomes. Most typically, utility analyses are calculated in financial terms, and over the years the model has been expanded to consider a host of financial and contextual factors (Boudreau, 1983; Sturman, 2000). Yet despite its sophistication, or perhaps because of it (Sturman, 2000 ), utility analyses may be viewed skeptically by the very audiences they are intended to influence (Latham and Whyte, 1994; Whyte and Latham, 1997), and thus the adoption of utility analysis has been minimal at best. 
The extensive literature on utility analysis also held out the hope for a research-driven, practically applicable means of combining HR metrics with improved decision making. This literature provided multiple and sophisticated methodological approaches to its implementation (e.g., Boudreau, 1983, 1991; Boudreau and Berger, 1985; Cascio and Boudreau, 2011; De Corte, 1994; Murphy, 1986; Sturman, 2000, 2001). Moreover, studies have even shown how the method can be used to demonstrate the practical implications of research findings and how they may be leveraged to improve HR decision making (e.g., Sturman, Trevor, Boudreau, and Gerhart, 2003). Unfortunately, like HR accounting, utility analysis relied upon a means of quantifying the economic value of employee performance, which is considered by many to be a major reason for the failure of the methodology to become practically widespread (Boudreau, 1991; Boudreau, Sturman, and Judge, 1994; Cascio, 1992; Macan and Highhouse, 1994; Schmidt, Hunter, McKenzie, and Muldrow, 1979). Thus, despite early indications of promise (e.g., Brogden, 1949; Brogden and Taylor, 1950; Cronbach and Gleser, 1957), and even some continued hope for its value as a theoretical tool (Sturman, 2012), utility analysis has not become the bridge between HR metrics and talent analytics.

Research on strategic HR management (SHRM) makes claims on a causal link between HR practices and organizational performance (Becker and Gerhart, 1996; Becker and Huselid, 1998; Guest, 1997; Huselid and Becker, 2011; Way, 2002). There is great value from this research, as the metrics used in these studies, such as surveys of high-performance work practices (Becker and Huselid, 1998; Huselid, 1995; Guthrie, 2001; Way, 2002), may be a starting point for HR metrics that have an established link with operational or financial outcomes. Yet this work remains arguably too macro (e.g., items include a simple assessment of 
whether a company uses pay-for-performance), making its influence on day-to-day HR metrics limited at best.

\section{TYPES OF METRICS}

Previous sections have established the difference between HR reporting, HR metrics, and talent analytics. In many ways, these differences parallel the levels of sophistication in talent analytics described by Cascio and Boudreau (2011), which progress from counting (HR reporting), to clever counting and insight (HR metrics), to influence (talent analytics). As with this categorization, one can see that there are different potential categories of HR metrics. Although the Cascio and Boudreau (2011) categorization focuses on sophistication, we turn to a categorization by Boudreau and Ramstad (2007), which categorizes metrics based on the nature of what is being measured. Specifically, Boudreau and Ramstad (2007) categorize HR metrics as (a) metrics of efficiency, (b) metrics of effectiveness, and ( c) metrics of impact. Each type of metric can play a role in helping to describe the results of a HR system, but each type also comes with its share of pitfalls. The benefits to talent analytics, though, will have to be built upon, and therefore dependent upon, the foundation of appropriate HR metrics (Cascio and Boudreau, 2011).

\subsection{Efficiency}

Often the first type of HR metric adopted is a measure of efficiency. Efficiency metrics focus on things like speed and ratios of resources to outcomes. Efficiency as a HR metrics concept has roots in and shares priorities with multiple other disciplines, such as the economic concepts of efficiency (Farrell, 1957). 
Typical efficiency metrics include measures like cost per hire, time to fill, training investment per high-potential employee promoted, and HR expenses as a proportion of all company expenses. Measures such as these help reveal the ability of these various HR functions to avoid waste-be it of time, money, or effort. While avoiding waste can clearly be beneficial, the danger of efficiency metrics is the potential interpretation that the focal processes are best off when the measures are either maximized or minimized. Yet, this is not always the case. For example, time to fill is not necessarily better as it approaches zero. Rather, it should be targeted at the optimal point where candidate quality and supply balance for the needs of the role and the organization.

HR operations, such as managing payroll or managing employee service centers, can also apply concepts of efficiency in the sense of minimizing waste. Here again, however, there is a natural tension in the concept of efficiency. For example, wait times for employees calling or chatting with a service center are necessarily a function of call volume, call complexity, center staffing, and center resources. A metric of wait times needs to balance the waste that a wait time represents for an employee against the waste that idle agents represent for the service center. Managing the request queue such that a "hotline" for higher-value customers is always answered first is a way of prioritizing waste differently for different segments.

The risk associated with efficiency as a focus of measurement is that efficiency can become a goal in and of itself, thus potentially creating inappropriate and strategically misaligned priorities. For example, time to fill a position may be used as a way of measuring how efficiently managers perform the staffing function. As companies want managers to pay attention to the ever-important staffing need and to keep a group’s productivity at desired levels, it makes sense to be concerned regarding this process, as overly long staffing times may be 
detrimental. Yet if the use of the metric leads to a goal of minimizing the metric, it may motivate undesirable behaviors. In this example, it would be possible to greatly reduce time to fill if no consideration were given to the qualifications of potential new hires. Effective construction of an HR metric must carefully balance the competing interests or tensions inherent in the process being monitored. So, while "time to fill" is essentially unidimensional as initially presented, the overall goal of the hiring process includes both quality and speed. Thus, to be useful, efficiency metrics should generally be designed to capture and balance multiple criteria, and be represented in such a way that reveals the critical tensions that exist between the various desired outcomes. Monitoring a single criterion or a unidimensional metric is likely to lead to unintended and undesired consequences.

\subsection{Effectiveness}

Having established the efficiency with which HR processes and services are delivered, many organizations move on to measuring the effectiveness of those products and services. Here, we evaluate the extent to which HR programs and services deliver the outcomes they were designed to deliver.

Effectiveness metrics commonly include measures like quality of hire, availability of ready-now successors for key leadership roles, differentiation in rewards, changes in attrition because of specific retention/attrition programs, and so forth. Whereas efficiency metrics generally examine a single resource to be minimized (e.g., expense, time), effectiveness metrics tend to balance aspects of resource expenditure with performance improvements. So whereas an efficiency metric may capture time to fill a position (implying a desire to minimize time), an effectiveness measure may capture the number of new hires that pass the probationary period (i.e., did the company hire individuals of sufficiently high quality that constituted acceptable 
employees?). Effectiveness metrics can be tuned to represent the quality of HR efforts in broad systems, such as recruitment, staffing, training, compensation, performance appraisal, labor relations, etc. The creation of effectiveness measure forces the HR decision maker to think beyond the resources needed to engage in a HR task, and particularly think about the benefits that should be exhibited by the system or intervention.

Effectiveness measures are not without pitfalls. Measuring effectiveness typically requires measurement at multiple process points, and it may require additional measurement beyond what naturally accumulates in the HR data systems or additional manipulation and cleaning in order to analyze the data effectively. These are not trivial challenges. Identifying the appropriate outcome measures requires a sophisticated understanding of the strategic purpose behind the processes undertaken, and generating measurements may require significant stakeholder engagement. It also requires the collection of appropriate HR data, not just easily measured HR data (Boudreau and Ramstad, 2007). These barriers may be sufficiently cumbersome to warrant using a sampling approach to measurement, rather than the populationlevel measurement that is more common among HR metrics. In addition, such metrics may not be perfectly accurate, as they will be approximated with error. Yet such error is acceptable as

long as the measure is getting at the type of information needed to inform a particular decision. A relevant measure approximated with error is more valuable than a different, perfectly estimated, but irrelevant measure.

\subsection{Impact}

Finally, the ultimate goal of many HR programs and services is, or should be, material impact on the business. Thus, a practice has emerged around metrics that attempts to gauge the impact of HR investments. These impact measures are driven by the same underlying philosophy 
that drove the classic utility analysis approach discussed above; however, where utility analyses attempted to create direct financial connections, impact analyses may measure HR programs against a variety of different business outcomes. Such outcomes may be customer-focused, process or HR-outcome-related, or financial in nature.

Impact measures differ from measures of efficiency and effectiveness in that they are more tightly aligned to unique company strategy and specific programs and services, and thus have fewer commonly shared measures across organizations. Thus, while measures of effectiveness are likely bounded to outcomes within the HR system, measures of impact typically expand beyond the HR system into business outcomes. Some outcomes may be widely visible across an industry, such as online ratings of satisfaction from third-party sources (e.g., Yelp! and TripAdvisor). Others may be very company-specific (e.g., a quality rating for a specific product or service or a measure of turnover for a particular group).

Although impact measures offer advantages over measures of efficiency and effectiveness, they have their own downsides. Impact measures generally seek to tie HR programs and processes to business outcomes, which creates multiple technical challenges. First, the data are rarely housed in compatible systems. Many organizations have separate HR hierarchies, which reflect the reporting lines in an organization, and business or finance hierarchies, which reflect how customer accounts, P\&Ls, or other business processes are reported. Second, while HR data are most often stored and measured at the individual level of analysis, business metrics are often tracked taken together, across teams, organizations, regions, product lines, or other segments. This creates levels-of-analysis problems. Third, the actual percentage of variance that any HR process or procedure has on actual business outcomes is likely to be relatively small, given all the other sources of variance in those outcomes, such as 
competitor actions, economic conditions, market position, inventory levels, and a host of other factors. Finally, many HR interventions are conducted at the enterprise level, and thus they lack sufficient variability to isolate truly the unique variance contributed by a specific process. This, in essence, is a restriction-of-range problem. These challenges do not mean that it is impossible or even inadvisable to conduct impact analyses. Rather, they serve as a caution to be thoughtful in isolating specific processes and specific outcomes, and to consider project-management strategies, like rolling implementation, that would allow for more variability and thus better signal detection. Companies can implement policies and collect data in a way consistent with quasi-experimental designs (Shadish, Cook, and Cambell, 2002). This allows HR data to be collected in such a way as to lend insights into the causes and effects of specific HR interventions. A key aspect to using HR metrics to inform decision making is not simply what is collected, but also how data are collected to allow for the most insight into the effects of HR actions.

\section{TALENT ANALYTICS}

Talent analytics is distinct from HR metrics in that the goal underlying talent analytics is to identify patterns that can inform strategic decisions (e.g., Boudreau and Ramstad, 2007). In this way, talent analytics functions as a decision science. The recent attention on talent analytics is exciting, as it is bringing opportunities to create better workplaces and better organizational outcomes. 


\subsection{HR Metrics and Talent Analytics Work Together}

The purpose of talent analytics is to yield better decisions. As such, metrics are needed both to identify problems and to evaluate solutions. For example, talent analytics may reveal that a particular university produces the most successful new hires in a particular area, thus causing the HR department to change its recruitment tactics. To reach this decision, HR metrics would have had to gauge the company's ability to hire, evaluate, and retain the graduates from that program, as well as from alternative programs. Similarly, talent analytics may reveal that a top risk factor for attrition is commute time. An organization may choose to address this through changing its recruiting practices, supporting employee relocation, or providing commuting options like buses, work-from-home, a satellite office, or hoteling options. Metrics would come into play both to help reveal the issue (i.e., metrics on turnover and commute time) and to monitor the success-efficiency, effectiveness, and impact-of the solutions used to address the commute-related attrition. It is talent analytics, though, that uses the HR metrics to drive HR decision making to understand the problem and yield a solution to it. As seen in these examples, a key distinction between HR metrics and talent analytics is that metrics tend to be ongoing, whereas talent analytics is oriented toward decision making. Measures of HR data, employee turnover and performance, other potential predictors, key outcomes, and comparisons among groups or across points in time are essential. Talent analytics, though, tends to occur in the context of discrete projects, with clear beginning and ends, used with the intent of moving from an identified problem to evaluating a solution.

As is most commonly applied, talent analytics is a challenging manual task. HR decision makers must act as researchers, looking for evidence of problems, either with a priori hypotheses (e.g., "I suspect that commute time increases turnover"), or as exploratory questions (e.g., "Does 
where we recruit affect the quality of our hires?"). Advances in HR data systems and big data methods that capitalize on large volumes of employee data, however, may yield more talent analytics indicators that function in a continually adaptive and even automated way. Advances in visual display of patterns in data, generally referred to as data visualization, are facilitating the process of talent analytics, allowing decision makers to search for patterns in data based on ad hoc or evolving hypotheses. To continue our attrition example from above, a dynamic data visualization of employee-movement data can enable a user to examine turnover data, expand those exits by key segment, and then drill into the top reasons why people leave that segment, all in a matter of moments. Simultaneously, big data systems can continuously scan quantitative and qualitative data, looking for patterns and predictors of organizational-critical outcomes. Such efforts are often aided by the use of extensive data dictionaries.

Data dictionaries are centralized repositories of information about data, providing information about the meaning of specific words, the relationships of those words to other words in the database, the usage of the words, format, and origin (McDaniel, 1994). Data dictionaries help in the evaluation of large qualitative sources of data, allowing patterns of meaning to be deduced from the vast content of unstructured qualitative data. Qualitative data dictionaries can be built and used to scan large volumes of employee surveys for indicators of managerial trouble or antecedents of turnover. In short, because of the combination of business needs, refinement in the HR field and in HR information, and the availability of technology applicable to HR issues and decision making, HR is now reaching new levels of sophistication. 


\section{FOSTERING TALENT ANALYTICS}

\subsection{Evolving Decision Science}

Decision science applies statistical analysis as part of strategic analysis to inform organizational investments and choices (Boudreau and Ramstad, 2007). This is a categorically different approach from the use of numbers in an HR system. Where HR reporting reflects what has happened, and HR metrics evaluate what is happening, the decision science around talent analytics provides recommendations about what should happen. Interest in and efforts at more sophisticated HR require a progression in sophistication (Cascio and Boudreau, 2011), as well as the tools and human capital within the HR group to engage in the decision science.

While industrial/organizational (I/O) psychology has a century-long history, broad interest outside of HR in using statistical approaches in talent management to drive broad business success is a fairly recent phenomenon (Davenport, Harris, and Shapiro, 2010). One of the key differentiators between the historical practice of I/O psychology and the emerging decision science around talent analytics is the tight and compelling connection to business strategy (Levenson, 2015). In this way, the current practice of talent analytics shares roots with HR accounting, utility analysis, and the impact metrics we discussed earlier. Talent analytics, however, tends to be focused explicitly on informing organizational decision making. A fair amount of the traditional practice of $1 / O$ psychology focused on optimizing processes that had already been identified as important. Thus, the analytic projects began after the key decisions as to where to invest had been made. Talent analytics often begins at a different point-identifying which problems to address in the first place, based on data describing the effects associated with prior decisions and circumstances. Furthermore, talent analytics often expands beyond the traditional areas of 1/O psychology, such as selection, performance appraisal, leadership, and 
employee performance, and it considers questions around items such as strategic workforce planning or team social structures. Additionally, where historically I/O psychology has relied heavily on experimental designs and parametric statistics, talent analytics tends to incorporate a wider range of analytic methods of both greater (i.e., machine learning and big data analytics) and lesser (i.e., data visualization) analytic complexity. The emergence of talent analytics has implications for data systems, measurement systems, the HR data teams that work with the data, and, perhaps most importantly, the opportunity for HR to influence organizational decisions.

While talent analytics holds tremendous promise for improving organizations, and the lives of the people in and around them, the field is not without challenges and risks. Perhaps the first obstacle is the actual human capital in HR itself. The implementation of talent analytics places a great burden on future HR managers, who need to possess sophistication in both the practices of HR and the analytical processes needed to employ talent analytics.

Once there are people in the field with the ability to implement talent analytics, the raw resources to create the opportunity for it are necessary. Many talent analytics projects require huge amounts of data; however, these data are often highly unstructured (Gandomi and Haider, 2015). Other data often include personally identifiable information, which requires special consideration (Guzzo et al., 2015). The risk of data breaches for such large volumes of information is non-trivial (Zafar, 2013). The rapid surge in interest in talent analytics means that many teams working on these problems lack useful training in employment law and ethical treatment of human subjects. Care must be taken to ensure the security and privacy of employees, information (Kovach, Hughes, Fagan, and Maggitti, 2002; Zafar, 2013).

Talent analytics also runs the risk of inadvertently using processes that are inappropriate or even illegal. Data-mining processes may find patterns in the data that are correlated with 
protected-class characteristics. For example, a system may find patterns in hiring successes that are associated with particular zip codes, but policies based on such patterns may lead to disparate impacts in hiring decisions. Care must be taken to ensure that the decision-making facilitated by talent analytics addresses all the goals of the HR department, including ethical standards, and it does not focus exclusively on maximizing a single goal (King, Tonidandel Cortina, and Fink, 2016).

\subsection{Fostering Metrics}

Many organizations are struggling to transition their HR data from a system designed to support transactions to a system designed to support measurement and analytics. Many HR data systems, particularly at established companies, were not built to be analyzable systems. Rather, many of them were optimized for handling transactions. This means many data are not stored or data are stored in ways that are difficult to disaggregate to analyzable component parts or impossible to link together across datasets or all of the above at once.

Companies with such systems may find that, for example, fields are overwritten to contain only the most recent information. In other cases, data are not stored at all. This is efficient from a storage standpoint, and it ensures that only the most recent information is used; however, it creates obstacles for conducting analyses of HR effectiveness. For example, if only the most current information is stored in a way that can be analyzed, it becomes difficult (and sometimes impossible) to examine individual performance over time. This may prevent analyses such as looking at which managers are most effective at developing and promoting women, or if certain interviewers are better at identifying future top performers, or what career paths are most efficient at producing effective leaders. A system designed only to be able to display and analyze the most current data loses the potential to consider what occurs over time. As so much about HR 
systems is the development of people over time in their jobs and careers, such deficiencies in HRISs preclude the ability to study many of the sort of questions that may most need to be addressed to assess the effectiveness of HR investments.

Data limitations are genuine constraints on organizations' ability to use HR metrics, which ultimately constrains the use of talent analytics. Although increasing availability and usability of commercially available HR data systems and tools with standard reporting packages is helping, many organizations still manage key processes, like succession plans, special retention-bonus programs, or expensive expatriate or executive-education processes, manually, on spreadsheets stored on an individual's hard drive. Notes from exit interviews may be handwritten and not transcribed, much less categorized or rated. Organizations built by acquisition may have entirely separate data systems, with different fields and values within those fields. Reorganizations may limit the ability to understand the impact of an intervention or process over time.

The implementation of talent analytics is challenged by more mundane data-system barriers as well. Cloud providers' contracts may not include sharing of raw data. Data-retention policies designed to protect privacy and mitigate risk may make things like impact measures, which necessarily require the passage of time and the ability to link across systems, impossible. Limitations like these can severely hobble the potentially very promising future of talent-analytic programs. 


\section{CONCLUSION}

HR metrics has a decades-long history of theoretical contributions that advance thinking but haven't definitively advanced the field. The emergence of talent analytics, in a milieu of increased global competition, increased data availability, increased general analytic sophistication, and increased availability of data storage and computing power, has finally cracked that challenge.

As we've seen above, effective talent analytics sits at the confluence of business imperatives and competitiveness, internal talent systems, and data infrastructure. Thus, to address this space effectively, a talent analytics team needs to encompass strong business acumen, deep HR content expertise, robust statistical and methodological depth, and wellinformed data systems capabilities. The interdisciplinary nature of these requirements means that individuals on the team must also be effective at collaborative problem solving, and good at respecting expertise beyond their own. Further, talent analytics teams should cultivate solid relationships with their legal counsel to ensure that issues such as privacy are thoughtfully considered, and requirements for Equal Employment Opportunity and Uniform Guidelines for Selection Procedures are unfailingly met.

Opportunities for sophistication in the HR function thus now exist in ways that have never existed before, and organizations are increasingly being motivated, and hiring those in HR with the right abilities, to take advantage of these opportunities. Together, HR metrics and talent analytics form a powerful approach to optimizing the utilization and experience of the chief resource of most organizations-the people. 


\section{REFERENCES}

Alliger, G. M., and Janak, E. A. 1989. Kirkpatrick's levels of training criteria: thirty years later. Personnel Psychology, 42(2), pp.331-42.

American Accounting Association Committee of Accounting for Human Resources. 1973. Report of the Committee on Human Resource Accounting. The Accounting Review Supplement, 48, pp.169-85.

Becker, B. E., and Gerhart, B. 1996. The impact of human resource management on organizational performance: progress and prospects. Academy of Management Journal, 39, pp.779-801.

Becker, B. E., and Gerhart, B. 1998. High performance work systems and firm performance. A synthesis of research and managerial implications. In G. R. Ferris, ed., Research in personnel and human resource management, Vol. 16, pp.53-101. Stamford, CT: JAi Press.

Becker, B. E., Huselid, M.A., and Ulrich, D. 2001. The HR scorecard: linking people, strategy, and performance. Boston: Harvard Business Press.

Bogomolov, A., Lepri, B., Ferron, M., Pianesi, F. et al. 2014. Pervasive stress recognition for sustainable living. In Pervasive Computing and Communications Workshops (PERCOM Workshops), 2014 IEEE International Conference on. pp.345-50. New York, NY: IEEE.

Bolino, M. C., Kacmar, K. M., Turnley, W. H., and Gilstrap, J. B. 2008. A multi-level review of impression management motives and behaviors. Journal of Management, 34, pp.1080109. 
Boudreau, J. W. 1983. Economic considerations in estimating the utility of human resource productivity improvements. Personnel Psychology, 36, pp.551-7.

Boudreau, J. W. 199i. Utility analysis for decisions in human resource management. In M. D. Dunnette and L. M. Hough, eds., Handbook of industrial and organizational psychology, Vol. 1, pp.621-745. Palo Alto, CA: Consulting Psychologist Press.

Boudreau, J. W., and Berger, C. J. 1985. Decision-theoretic utility analysis applied to external employee movement. Journal of Applied Psychology, 70, pp.581-612.

Boudreau, J. W., and Ramstad, P. M. 2007. Beyond HR: the new science of human capital. Boston: Harvard Business School Press.

Boudreau, J. W., Sturman, M. C., and Judge, T. A. 1994. Utility analysis: what are the black boxes and do they affect decisions? In N. Anderson and P. Herriot, eds., Assessment and selection in organizations, pp.77-96. John Wiley \& Sons: New York.

Briner, R. B., and Rousseau, D. M. 2011. Evidence-based I-0 psychology: not there yet. Industrial and Organizational Psychology, 4, pp.3-22

Brogden, H. E. 1949• When testing pays off. Personnel Psychology, 2, pp.171-83.

Brogden, H. E., and Taylor, E. K. 1950. The dollar criterion: applying the cost accounting concept to criterion construction. Personnel Psychology, 3, pp.133-54.

Bromiley, P., and Rau, D. 2015. Operations management and the resource based view: another view. Journal of Operations Management, 41, pp.95-106.

Cascio, W. F. 1981. Costing human resources: the financial impact of behavior in organizations. Cincinnati: Southwestern. 
Cascio, W. F. 1992. Assessing the utility of selection decisions: Theoretical and practical considerations. In N. Schmidt, W. C. Borman, and Associates, eds., Personnel selection in organizations, pp.310-40. San Francisco: Josset-Bass.

Cascio, W., and Boudreau, J. 2011. Investing in people: financial impact of human resource initiatives, 2nd edn. Upper Saddle River, NJ: Pearson Education Inc.

Cascio, W., and Boudreau, J. 2014. Evidence-based management at the bottom of the pyramid: why human resources standards and research must connect more closely. Oxford handbooks online, Nov. 2014. http://www.oxfordhandbooks.com/view/lo.1093/oxfordhb/9780199935406 .ooi.0001/ oxfordhb-97 80199935406-e-12.

Chamorro-Premuzic, T., Winsborough, D., Sherman, R. A., and Hogan, R. 2016. New talent signals: shiny new objects or brave new world? Industrial and Organizational Psychology: Perspectives on Science and Practice, 9(3), pp.621-40.

Cherian, J., and Farouq, S. 2013. A review of human resource accounting and organizational performance. International Journal of Economics and Finance, 5, pp.74-83.

Cronbach, L. J., and Gleser, G. C. 1957· Psychological tests and personnel decisions. Urbana: University of Illinois Press.

Davenport, T. H., Harris, J., and Shapiro, J. 2010. Competing on talent analytics. Harvard Business Review (Oct.), pp.2-6.

De Corte, W. 1994 - Utility analysis for the one-cohort selection-retention decision with a probationary period. Journal of Applied Psychology, 79, pp.402-11. 
de Montjoye, Y. A., Quoidbach, J., Robie, F., and Pentland, A. S. 2013. Predicting personality using novel mobile phone-based metrics. In SPB, Social computing, behavioral-cultural modeling and prediction, pp.48-55. Berlin: Springer.

Denton, G. A., and White, B. 2000. Implementing a balanced-scorecard approach to managing hotel operations: the case of White Lodging Services. Cornell Hotel and Restaurant Administration Quarterly, 41(1), pp.94-107.

Dooney, J. 2013. Benchmarking human capital metrics. SHRM Online (Mar. 26). http://www.shrm.org/templatestools/toolkits/pages/benchmarkinghumancapitalmetrics.as px. Accessed 1/26/2016.

Dulebohn, J. H., and Johnson, R. D. 2013. Human resource metrics and decision support: a classification framework. Human Resource Management Review, 23, pp.71-83.

Farrell, M. J. 1957· The measure of productive efficiency. Journal of the Royal Statistical Society Series A, 225, pp.252-67.

Fitz-Enz, J. 2010. The new HR analytics: predicting the economic value of your company's human capital investment. New York: American Management Association.

Flamholtz, E.G. 1999· Human resource accounting: advances in methods and applications, 3rd edn. New York: Spring Science+ Business Media.

Gandomi, A., and Haider, M. 2015. Beyond the hype: big data concepts, methods, and analytics. International Journal of Information Management, 35(2), pp.137-44. 
Grohmann, A., and Kauffeld, S. 2013. Evaluating training programs: development and correlates of the questionnaire for professional training evaluation. International Journal of Training and Development, 27(2), pp.135-55.

Guest, D. E. 1997· Human resource management and performance: a review and research agenda. International Human Resource Management, 8, pp.263-76.

Guthrie, J. 2ooi. High involvement work practices, turnover, and productivity: evidence from New Zealand, Academy of Management Journal, 44, pp.180-90.

Guzzo, R. A., Fink, A. A., King, E., Tonidandel et al. 2015. Big data recommendations for industrial- organizational psychology. Industrial and Organizational Psychology: Perspectives on Science and Practice, 8, pp.491-508.

Hitt, M. A., Carnes, C. M., and Xu, K. 2015. A current view of resource based theory in operations management: a response to Bromiley and Rau. Journal of Operations Management, 41(10), pp.107-9.

Holton, E. F. 1996. The flawed four-level evaluation model. Human Resource Development Quarterly,7(1), pp.5-21.

Huselid, M. A. 1995 The impact of human resource management practices on turnover, productivity, and corporate financial performance. Academy of Management Journal, 38, pp.635-70.

Huselid, M.A., and Becker, B. E. 2011. Bridging micro and macro domains: workforce differentiation and strategic human resource management. Journal of Management,J7, pp.421-28. 
Huselid, M. A., Becker, B. E., and Beatty, R. W. 2005. The workforce scorecard: managing human capital to execute strategy. Boston: Harvard Business School Press.

Kaplan, R. S., and Norton, D 1992. The balanced scorecard: measures that drive performance. Harvard Business Review, 70(1), pp.71-9.

Kerr, S. 1975. On the follow of rewarding A while hoping for B. Academy of Management Journal, 28, pp.769-83.

King, E., Tonidandel, S., Cortina, J., and Fink, A. A. 2016. Building understanding of the data science revolution and IO psychology. In S. Tonidandel, E. King, and J. Cortina, eds., Big data at work, pp.1-15. New York: Taylor \& Francis/Routledge.

Kirkpatrick, D. L. 1959. Techniques for evaluating training programs. Journal of American Society for Training and Development, 23, pp.11-12.

Kirkpatrick, D. L., and Kirkpatrick, J. D. 2005. Transferring learning to behavior. San Francisco: Berrett-Koehler Publishers.

Kovach, K., Hughes, A., Fagan, P., and Maggitti, P. 2002. Administrative and strategic advantages of HRIS. Employment Relations Today, 29, pp.43-8.

Lambiotte, R., and Kosinski, M. 2014. Tracking the digital footprints of personality. Proceedings of the IEEE, 102(12), pp.1934-9.

Latham, G. P., and Whyte, G. 1994. The futility of utility analysis. Personnel Psychology, 47, pp.31-46.

Levenson, A. 2015. Strategic analytics: advancing strategy execution and organizational effectiveness. San Francisco: Berrett-Koehler Publishers. 
Macan, T. H., and Highhouse, S. 1994. Communication the utility of human resource activities: a survey of 1/O and HR professionals. Journal of Business Psychology, 8, pp.425-36.

McDaniel, G., ed. 1994. IBM dictionary of computing. New York: McGraw-Hill.

Mirvis, P. H., and Lawler, E. E. 1983. Systems are not solutions: issues in creating information systems that account for the human organization. Accounting, Organizations and Society, 8(2-3), pp.175-90.

Murphy, K. R. 1986. When your top choice turns you down: effect of rejected offers on the utility of selection tests. Psychological Bulletin, 99, pp.133-8.

Noe, R. A. 2013. Employee training and development, 6th edn. New York: McGraw-Hill.

Paki, H., and Azar, S. F. 2015. Identification and prioritization of obstacles of implementation of human resource accounting system by TO PSIS. Journal of Management Sciences, 1(3), pp.23-31.

PWC. 2015. Trends in people analytics. http://www.pwc.com/us/en/hrmanagement/publications/assets/pwc-trends-in-the-workforce-2015.pdf. Accessed Jan. 26, 2016.

Roselender, R., and Dyson, J. R. 1992. Accounting for the worth of employees: a new look at an old problem. British Accounting Review, 24, pp.311-29.

Rousseau, D. M. 2006. Is there such a thing as evidence-based management? Academy of Management Review, 31, pp.256-69.

Shadish, W. R., Cook, T. D., and Campbell, D. T. 2002. Experimental and quasi-experimental designs for generalized causal inference. Houghton, Mifflin and Company. 
Salas, E., Wildman, J. L., and Piccolo, R. F. 2009. Using simulation-based training to enhance management education. Academy of Management Learning \& Education, 8(4), pp.559-n

Scarpello, V., and Theeke, H. A. 1989. Human resource accounting: a measured critique. Journal of Accounting Literature, 8, pp.265-80.

Schmidt, F. L., Hunter, J. E., McKenzie, R. C., and Muldrow, T. W. 1979. Impact of valid selection procedures on work-force productivity. Journal of Applied Psychology, 64, pp.609-26.

Snyder, R. A., Raben, C. S., and Farr, J. L. 1980. A model for the systematic evaluation of human resource development programs. Academy of Management Review, 5, pp.431-44.

Sturman, M. C. 2012. Employee value: combining utility analysis with strategic human resource management research to yield strong theory. In N. Schmitt, ed., Oxford handbook of personnel assessment and selection, pp.768-92. Oxford: Oxford University Press.

Sturman, M. C. 2000. Implications of utility analysis adjustments for estimates of human resource intervention value. Journal of Management, 26, pp.281-99.

Sturman, M. C. 2001. Utility analysis for multiple selection devices and multiple outcomes. Journal of Human Resources Costing and Accounting, 6, pp.9-28.

Sturman, M. C., Trevor, C.O., Boudreau, J. W., and Gerhart, B. 2003. Is it worth it to win the talent war? Evaluating the utility of performance-based pay. Personnel Psychology, 56, pp.997-1035. 
Taras, V., Caprar, D. V., Rottig, D., Sarala, R. M. et al. 2013. A global classroom? Evaluating the effectiveness of global virtual collaboration as a teaching tool in management education. Academy of Management Learning \& Education, 12(3), pp.414-35.

Taylor, H. C., and Russell, J. T. 1939. The relationship of validity coefficients to the practical effectiveness of tests in selection: discussion and tables. Journal of Applied Psychology, 23, pp.565-78.

Way, S. A. 2002. High performance work systems and intermediate indicators of firm performance within the US small business sector. Journal of Management, 28, pp.765-85.

Whyte, G., and Latham, G. P. 1997. The futility of utility analysis revisited: when even an expert fails. Personnel Psychology, 50, pp.601-10.

Yorks, L., Beechler, S., and Ciporen, R. 2007. Enhancing the impact of an open-enrollment executive program through assessment. Academy of Management Learning \& Education, 6(3), pp.310-20.

Zafar, H. 2013. Human resource information systems: information security concerns for organizations. Human Resource Management Review, 23, pp.105-13. 